Justyna Giczela-Pastwa

University of Gdańsk

justyna.giczela@ug.edu.pl

\title{
Translation theory from students' perspective: an indispensable professional prerequisite or a tedious curricular obligation?
}

\section{Introduction ${ }^{1}$}

The importance of translation theory teaching seems to be a recurring theme in researchers' reflections on training and curricula. Apparently, there is little, if any, disagreement over the issue. As Lederer [2007: 33] observes,

To produce expert translators, having trainees translate a lot is not sufficient. Translation is a complex operation and theory helps in generalizing and systematizing problems. Within its general frame, trainees are able to take some distance from specific details and assign their respective roles to the text, its content, loyalty, the translator's initiatives, etc. As a result, their approach to translation problems will become more self-assured.

The opinion of Chesterman [1996] is similarly unequivocal and even more powerful. While discussing the concept of a translation-meme pool, which permanently determines the way translator trainees will perceive and perform translation in their future careers, he mentions a few "risks of drowning". The first on the list of detrimental fallacies are atheoretical attitudes:

By this I mean the belief among some translators that one "does not need" a translation theory in order to be able to translate. This is pure self-deception:

I would like to sincerely thank Dr Ross Aldridge, University of Gdańsk, for his generous and invaluable help in proofreading this paper. 
a theory is basically a view of something, a conception. To translate with no theory would be impossible [ibidem: 64].

However, the question may arise how the very concept of theory, or specifically translation theory, is defined by scholars when expressing their views on the role it plays in contemporary translation training. Before I refer to the definitions that I find particularly important, let me mention the list of quotations discussed by Chesterman in his seminal book [2000: 43-46]. As the author observes, the quoted explanations reveal diverse points of view and appear to the reader as contradictory [ibidem: 44]. The discrepancies prove that defining the notion of a theory is an extremely challenging task, let alone formulating a comprehensive translation theory.

Lederer [2007: 16] defines theory "as a set of principles used to explain a class of phenomena, the phenomena of interest in our case being those of translation". A similar view is presented by Chesterman [2007: 1], who takes "(better) understanding to be the general goal of any theory. A theory of translation is thus a view of translation - or some part or aspect of it - which helps us to understand it better"; "a theory is an instrument of understanding". Returning to the applied aspect of translation theories and their validity for translation practice, Chesterman observes that "one of the best contributions translation scholars can make to the work of professional translators is to study and then demonstrate the links between different translation decisions or strategies and the effects that such decisions or strategies seem to have on clients and readers and cultures, both in the past and in the present, under given conditions" [Chesterman and Wagner, 2002: 5]. On the other hand, Pym [2010: 2] describes theories as "scenes set by ideas about what could or should be in a translation", and in this way closely links translation theory and practice, although in a more prescriptive mode than the two writers quoted above.

Practitioners, however, do not share the optimistic and confident view of translation scholars. The most perceptible is the voice of Wagner, who starts her famous dialogue with Chesterman [Chesterman, Wagner, 2002] with a sharp statement ("Translation theory? Spare us..."), quoted as a typical reaction of a practicing translator when asked about the usefulness of translation theory. Wagner [cf. ibidem: 1] backs her statement 
up with the sceptical views of other practitioners, i.e. Berglund and Cross. Similar overtones can be traced in statements by Robinson ("It is time to offer translators tools, not rules", 1991: xvi, quoted in Baer and Koby, 2003: vii) and Pym ("there must be doubt about the extent to which academic research can directly enhance translation skills", 2011: 482). Moreover, Pym directly addresses the dispute between translation scholars and practitioners by noticing the ever-changing nature of "the lists of competencies (as in the various working versions of the European Masters in Translation), where the 'theory' components tend to come and go according to the background of the person drawing up the list" [2011: 483].

A possible explanation of practitioners' suspicion has been offered by Baer and Koby [2003: vii]:

The prejudice against theory on the part of practitioners is understandable, for while translation may be "the world's second oldest profession," it has only recently been institutionalized as a unique discipline within the academy. Its position outside or on the margins of scholarship has helped to foster a profound scepticism toward translation theory, fueled by popular beliefs that translators are born, not made, or that translation is something that is learned on the job, not in the classroom.

As can be noticed, teaching theory to translator trainees has been tackled and discussed by a number of researchers [cf. also Shiyab, 1996; Calzada Pérez, 2005; Piotrowska, 2016]. However, to the best of my knowledge, little attention has been paid so far to the opinions of translator trainees themselves. Apparently, it is generally assumed that students who have just been gaining experience, are not supposed to form relevant and long-standing opinions. However, being well informed about their expectations and reservations concerning translation theories (teaching) may allow trainers to adjust the material and manner of delivery to their needs, to be one step ahead and competently direct and facilitate their development, in line with a student-centred approach. The study presented below was designed and conducted in order to gain insight into the views of translator trainees and their possible evolution. 


\section{Research Design}

The main study was carried out in October and November 2012, and was accompanied by a short follow-up questionnaire in January 2013. Participants in the study were studying at the Centre for Translation Studies, University of Gdańsk, Poland, both at the BA and MA levels. The overall number of subjects who took part in the study amounts to 117, and splits fairly evenly into five groups, analogous to the year of study:

Chart 1. The distribution of participants in the study

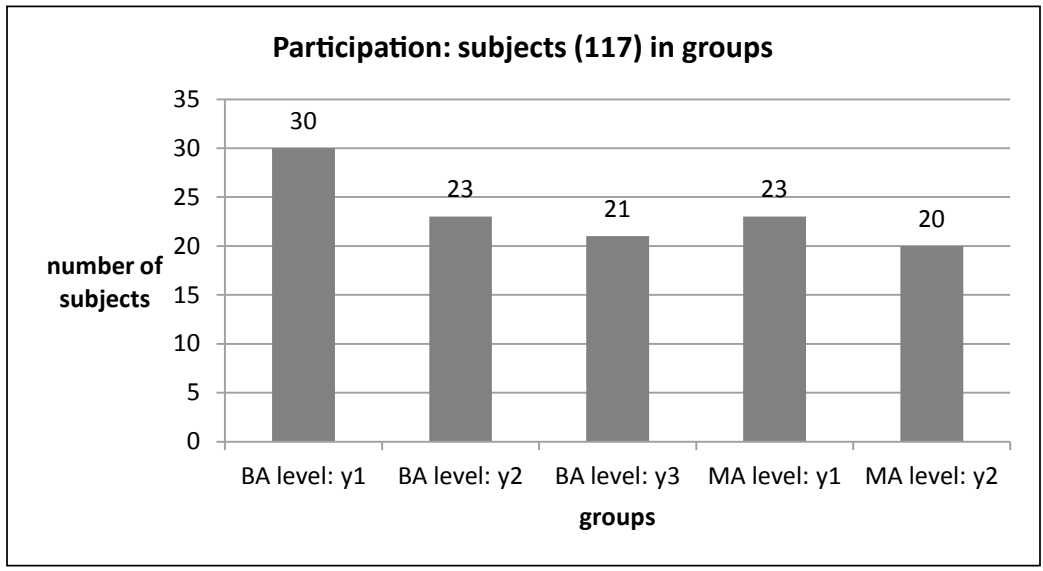

As of the academic year 2012-2013, translation theory was taught to the subjects mainly in the form of separate courses, included in both BA and MA programmes (90 and 60 teaching hours respectively), although passing references to selected theoretical approaches were also made during practical courses. Obviously, during BA and MA seminars the students regularly related their analyses to chosen theories; however, it was assumed that they had become acquainted with the theory of translation before seminars began.

First, all the participants were asked to fill in the main survey (S1) which consisted of four questions (Q1 to Q4). While answering the first one (Q1), concerning subjects' general attitude towards translation theory, students could either use response set wording alone, or optionally add their own comments to fully support the answer they had chosen. 
Two subsequent questions (Q2 and Q3) were formulated with ready answers to choose from, and finally the last question (Q4) was open-ended and aimed at collecting more qualitative data. In order to gain additional knowledge from existing results, i.e. the outcomes of S1, triangulation procedure was applied [cf. e.g. Hansen, 2005; Alves, 2003] and a short follow-up survey (S2) was designed and distributed to the MA-level subjects.

The idea behind S2 was to assess the respondents' previous experience of TS and to determine if the most frequent answers to the questions included in $\mathrm{S} 1$ are motivated by former training in translation theory or by relatively little awareness of any theoretical frameworks. It has been tentatively assumed that a BA degree in TS, obtained from the University of Gdańsk or any other tertiary education unit, is a proof of some familiarity with at least the most popular theories of translation. A BA degree in English Studies or any other field has been equated with little or no previous training in theoretical aspects of translation.

\section{Chart 2. The distribution of former experience with translation theory among} MA-level participants

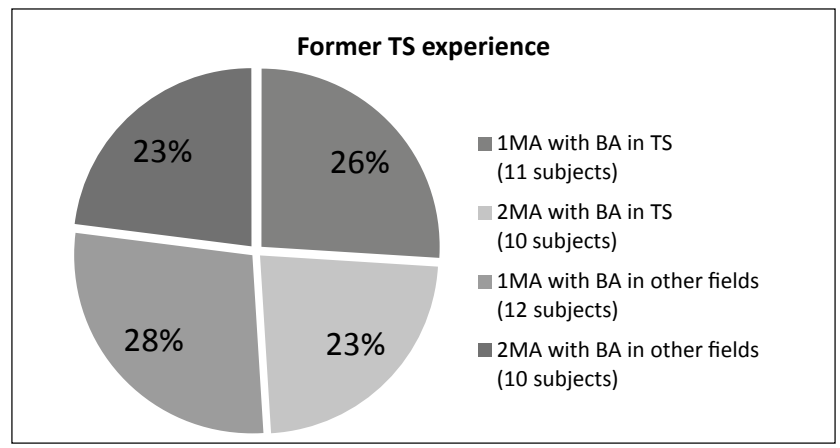

As may be noticed, as far as S2 is concerned, the total number of subjects splits into four even groups. At each level an almost identical number of persons have a BA degree in TS (11 and 10 subjects in 1MA and 2MA groups respectively) and a similar number of persons in each of the MA groups have a BA degree in a field different from TS, mostly in English Studies (12 and 10 subjects in 1MA and 2MA groups 
respectively). The results of $\mathrm{S} 2$ make it justifiable to assume that since the whole batch of MA respondents divides into two even groups of the translation theory-trained and the novices, the 1MA and 2MA may be considered as comparable and the discrepancies between the answers of 1MA and 2MA respondents should be treated with utmost attention.

\section{Research Hypotheses and Background}

At the outset of the study it was assumed that translator trainees' attitudes towards translation theory change with their growing experience and professional maturity. Apparently, novice translators should demonstrate a growing need for familiarity with theoretical reflection on translation, understood here not only as tricks of the trade, but also as wider frameworks which allow translation practitioners to make their decisions with greater composure and self-confidence.

As the etymology of the word 'theory' suggests, referred to by Pym, theorizing describes looking at a view, and therefore "A theory sets the scene where the generation and selection process takes place. Translators are thus constantly theorizing as part of the regular practice of translating" [Pym, 2010: 1]. Whenever individual theorizing is confronted with alternative views on a particular translation issue and supported with a coherent set of arguments, it develops into a comprehensive theory [ibidem: 2]. Adopting the approach presented, it can be deduced that correctly formulated theories should stem from experience, reflect practical expertise and serve as a point of reference and a guideline for their followers. Consequently, as sources of ready-made help in trouble, translation theories should be learnt and eagerly applied by translator trainees. The present study aimed at testing the above-mentioned assumption about increasing awareness of the significance of translation theory as a result of the gradual professional development of novice translators.

\section{Research Outcomes}

This section focuses on the results of S1 as the main part of the study. The outcomes of the follow-up S2, presented briefly in the Research Design section, show that by coincidence the batch of MA subjects was 
an ideal group to be surveyed in order to learn more about trainees' attitudes to the applicability of translation theory and that $\mathrm{S} 1$ results in this group can be viewed as informative.

The opening question of S1 concentrates on a trainee's subjective evaluation of the influence translation theory has had on their translation routine and the role the theory plays for them $(\mathrm{Q} 1$ : How would you assess the impact of translation theory on your translation practice?). The subjects were to choose from four options: indispensable (I can hardly imagine translating without the knowledge of translation theory; thanks to knowing a number of theoretical statements and approaches I may I have become more aware of practical nuances.); almost useful (I am positive that translation theory enriches / will enrich my practice, even though at times it is difficult for me to apply it consciously.); mainly irrelevant ( $A$ few theoretical statements make sense, but a majority seem irrelevant for translation practice.); pointless (I see no point in learning about theory; while translating I use my intuition and I do not remember what all the big names say.). Apart from choosing any of the options, the respondents could provide additional explanation using the lines provided below the set wording. The popularity of each ready-made answer among BA-level subjects is shown on the charts below:

Chart 3. The distribution of $Q 1$ answers in $1 \mathrm{BA}$ group

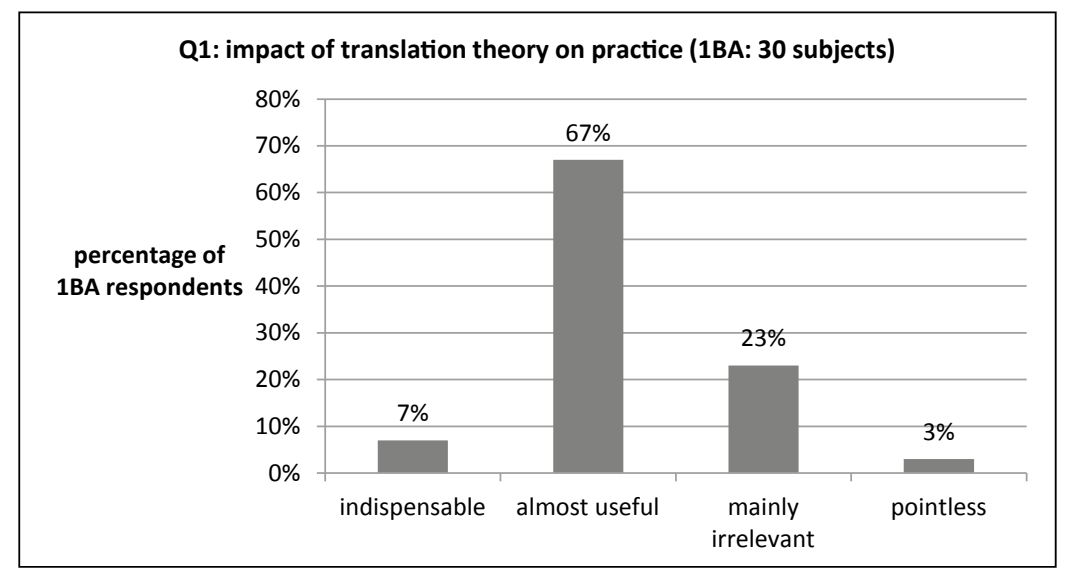


Chart 4. The distribution of $Q 1$ answers in $2 B A$ group

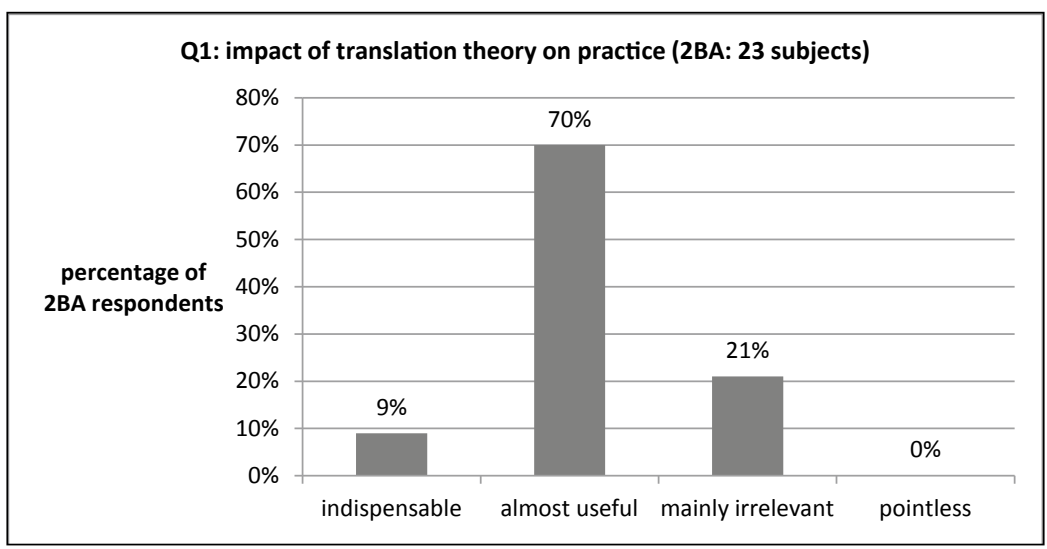

Chart 5. The distribution of $Q 1$ answers in 3BA group

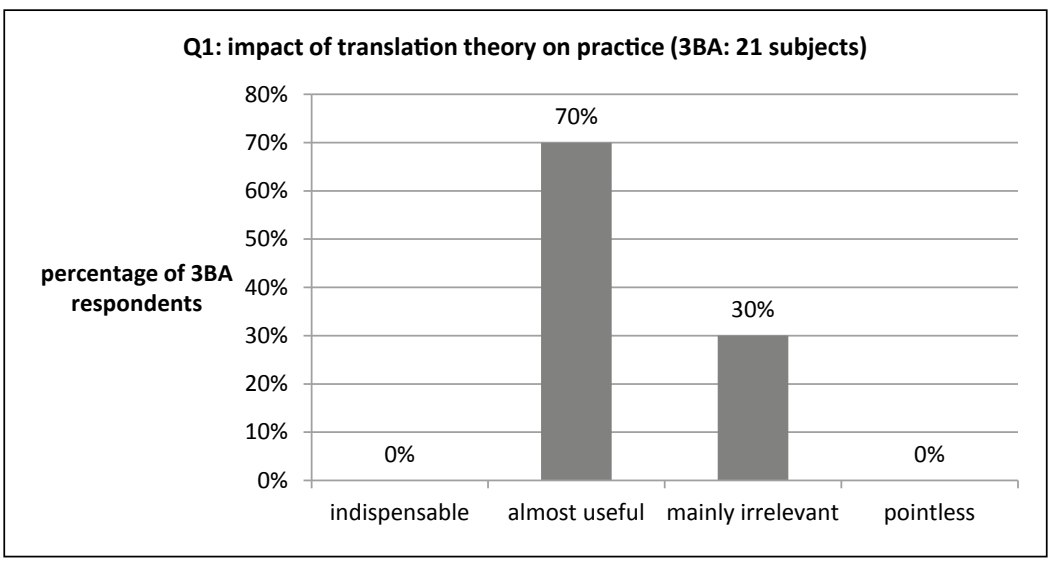

All BA-level subjects respond to this essential question in a similar way: in each group approximately $70 \%$ state that translation theory has considerably enriched or will surely enrich their practice, even though at times they do not apply it consciously. The second most popular answer was to assess the majority of theoretical statements as mainly irrelevant for practice - this answer was chosen by around $20 \%$ of $1 \mathrm{BA}$ and 2BA students, and as much as $30 \%$ of $3 \mathrm{BA}$ students. Extreme options 
(indispensable or pointless) were chosen by few subjects from 1BA and 2BA groups: 4 subjects out of $74 \mathrm{BA}$ respondents opted for indispensable, and only 1 person out of 74 chose pointless.

What may be more interesting, however, are the additional comments which the respondents made while answering Q1. Those 1BA students who chose the almost useful answer often added that their first tool while translating was their intuition, nevertheless, if in trouble, they try to find a solution with the help of theory. These comments bring to mind the approach of natural translators, described by Harris and Toury [cf. Gentile, 1996; Antonini, 2011]. One of the most up-todate definitions presents a natural translator as "an untrained and very often unremunerated bilingual individual who acts as a linguistic and cultural (inter)mediator in a variety of formal and informal contexts and situations" [ibidem: 102]. However, what links the comments with the notion in question more directly is the attitude natural translators have towards translation, characterized by Harris as a conviction that "the ability to translate and interpret is not the exclusive realm of professionals, but a natural aptitude for bilingual speakers" [ibidem] and that "translation is done by bilinguals in everyday circumstances without special training for it" [Harris, 1976: 96].

As far as 2BA students are concerned, their comments are more varied and show growing experience: they underline the way in which theory makes them more aware of the whole process and point to certain flaws typical of translation theories (e.g. theories are repetitive; theories present obvious things). It can be noticed that they remain slightly sceptical about the usefulness of the metalanguage of translation, arguing that customers do not care about and do not know all the 'fancy names'.

The comments of 3BA students reflect even greater experience: they again describe translation practice as a mostly instinctive and intuitive activity, but define this 'intuition' as an ability formed on the basis of theoretical statements and ideas learnt about during classes. Moreover, a few of them observe that theory seems most useful at the revision stage when it may make the translator confident that the decisions they have taken give satisfying results. Interestingly, what is viewed as a drawback by their younger peers, now becomes perceived as an advantage: a few respondents underline that with the help of theory, translators are able to 
support the decisions they have taken with the use of 'proper wording' and thus convince clients/other translators that they are professionals.

As was the case with BA-level respondents, analogous inner similarity may be observed in the case of MA-level subject. However, the difference in the way BA and MA subjects answer Q1 is immediately noticeable. The charts below reflect the choices of 1MA and 2MA groups respectively:

Chart 6. The distribution of $Q 1$ answers in 1MA group

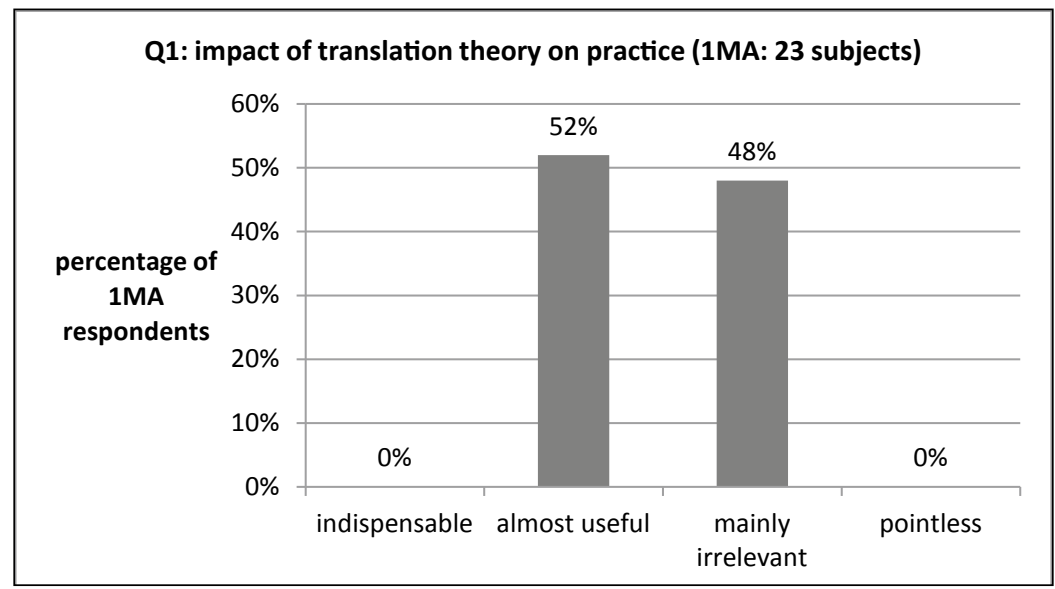

Chart 7. The distribution of Q1 answers in 2MA group

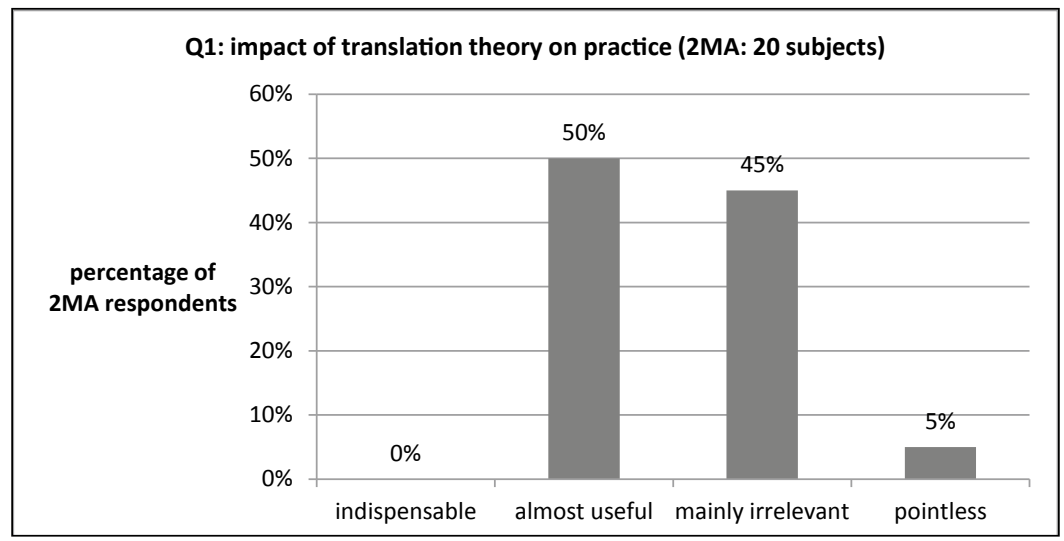


In comparison with BA students' considerable enthusiasm for translation theory, reflected in the popularity of the almost useful answer, the attitude of MA students seems more sceptical. Even though the option preferred by their younger peers remains most frequently chosen among $1 \mathrm{MA}$ students and is selected by a half of 2MA students, the drop in the percentage of its adherents is noticeable.

Two subsequent questions in S1, i.e. Q2 (What is in your opinion an optimum share of theoretical and practical courses in your programme?) and Q3 (As far as the content of a theoretical course is concerned, would you prefer to learn in detail about one particular approach advocated by the trainer? / learn about as many approaches as possible, and choose for yourself?) were meant to direct respondents' attention to the actual framework of teaching/learning translation theory.

In Q2 the respondents choose from four ready-made answer options: a) more theory, less practice (more theoretical, fewer practical; once someone teaches me some theory, I can put it into practice myself); b) equal halves; c) less theory, more practice (fewer theoretical, more practical: practice makes perfect); d) only practice (only practical; I can read the theory on my own if I need it). It is noteworthy that the first answer option was not chosen by any BA- or MA-level subject, that is why it has been excluded from the charts. Obviously, the omission of this answer option by the participants suggests that their general attitude to translation - even when facing approaching deadlines for BA or MA thesis submission - is more applied than purely academic, and that the schedule of the programme provides a satisfactory amount of theory teaching.

The choices of BA-level respondents are presented in detail below: 
Chart 8. The distribution of $Q 2$ answers in 1BA group

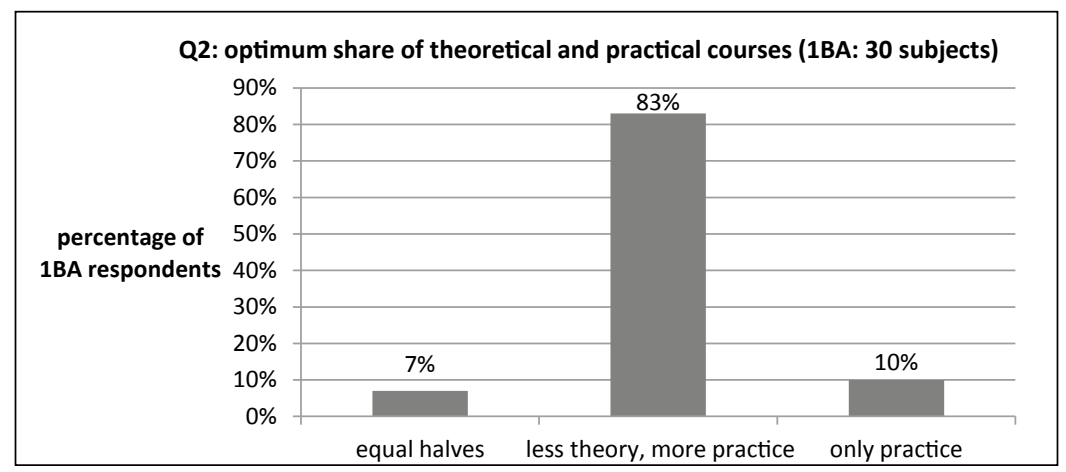

Chart 9. The distribution of Q2 answers in 2BA group

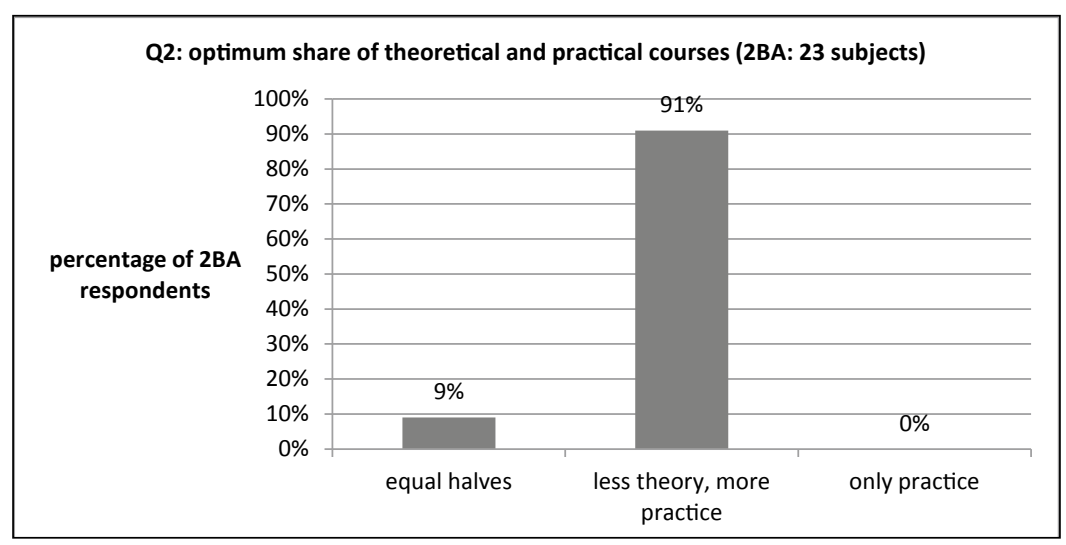


Chart 10. The distribution of $Q 2$ answers in 3BA group

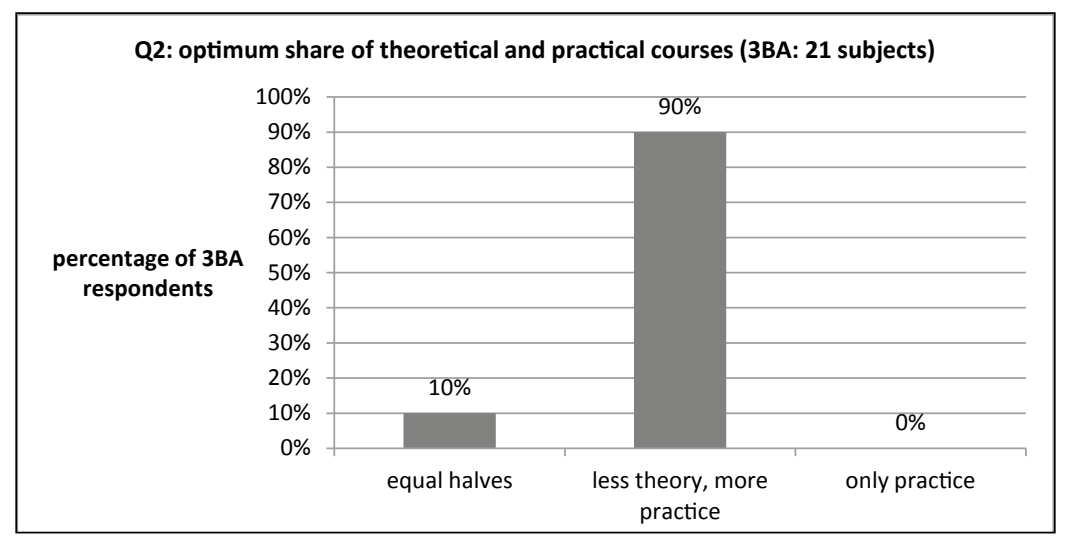

Again, as in the case of Q1, each of the BA-level groups responded in a similar way, with an overwhelming majority suggesting that theoretical courses should give way to practical courses. It is interesting to notice that the percentage of equal halves option supporters has slightly increased from $7 \%$ in the $1 \mathrm{BA}$ group, to $9 \%$ in $2 \mathrm{BA}$ and $10 \%$ in the $3 \mathrm{BA}$ groups, but an interpretation that it reflects growing awareness of the importance and usefulness of translation theory would be too far-fetched, considering the scale of the increase. On the other hand, the absence of voices in favour of a solely practical orientation of the programme in 2BA and 3BA groups, in contrast with 10\% support expressed in 1BA group, should be taken into account and treated as a possible sign of a developing appreciation of theory. 


\section{Chart 11. The distribution of $Q 2$ answers in 1MA group}

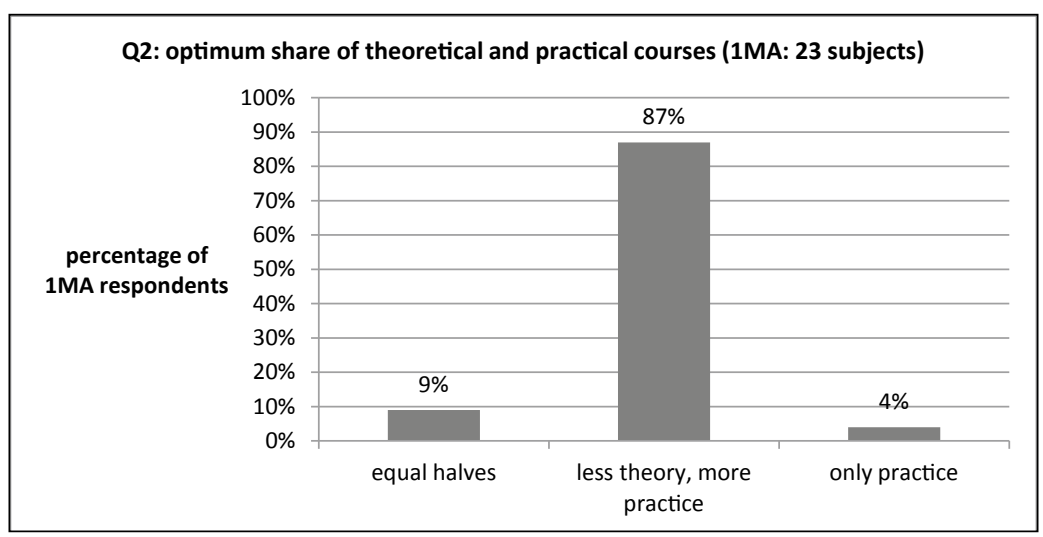

Chart 12. The distribution of $Q^{2}$ answers in 2MA group

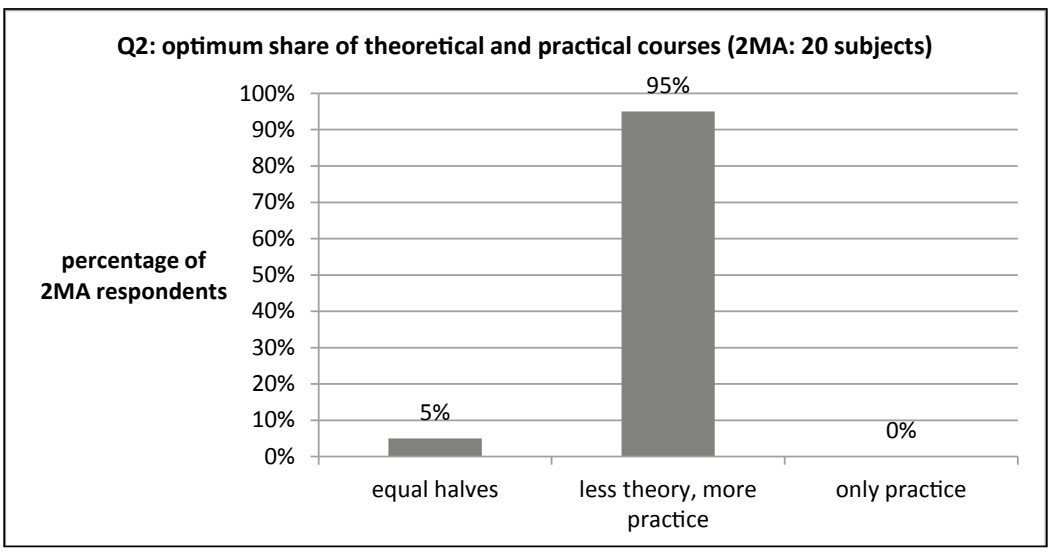

Let us now compare BA-level answers with MA-level choices. Even though the differences between BA- and MA-level answers are not striking, I would suggest that the choices of MA subjects may indicate a certain disillusionment with the value of translation theory. The percentage of equal halves option supporters is the lowest in the case of 2MA students and simultaneously, the supporters of the less theory, more practice option are the most numerous in this group. 
In the next question the subjects were to choose between unity and variety, i.e. in-depth familiarity with one theory or general comprehension of many theoretical approaches to translation. Even though there are subtle percentage differences between particular groups, the majority of respondents prefer to learn about as many theoretical stances as possible. This option has been chosen by $\min .87 \%$ in the case of 1MA to max. $100 \%$ in the case of $2 \mathrm{BA}$ students. The results may be considered positive feedback on the most popular design of translation theory courses, which are typically delivered in the form of chronologically ordered or problem focused overviews of diverse theories.

Last but not least, the final question of S1 concerns the expectations the subjects have about a thorough and helpful translation theory $(\mathrm{Q} 4$ : What do you expect from a comprehensive theory of translation? Please list no more than five expectations, if possible, in order of importance.). No answer options were provided, because this time I aimed at gathering more qualitative data and observing the metalanguage used by the respondents while discussing theoretical issues. As the wording and length of the answers were very varied, it is impossible to present a comprehensive report; however, I tried to trace general tendencies.

It is noteworthy that in the $1 \mathrm{BA}$ and $2 \mathrm{BA}$ groups as much as $20 \%$ and $26 \%$ of respondents respectively did not provide any answer to Q4. The lack of an answer may be interpreted primarily as a sign of unfamiliarity with the metalanguage and an inability to quickly and concisely list one's own expectations due to limited translation experience. This interpretation may be supported by the fact that in the more experienced groups the lack of an answer to Q4 was marginal. ${ }^{2}$

The majority of 1BA respondents expected that a comprehensive theory would first of all instruct them in appropriate translation strategies and techniques ${ }^{3}$ - it was the hope of almost half of the group (47\%). Often a particular translation issue that a theory should help to solve

$2 \quad 3 \mathrm{BA}$ group - n/a (all the subjects provided answer to Q4); 1MA and 2MA groups - only one respondent in each group (i.e. $4 \%$ and $5 \%$ respectively) did not answer Q4.

3 However, it should be underlined that the wording used by 1BA subjects is rather general: most often the respondents write about ways to translate certain things / ways how to deal with / tips how to cope with, etc. Three subjects (10\%) use the word strategy, one (3\%) - method and one (3\%) - technique. 
is mentioned, e.g. idioms, proper nouns, collocations, culture-specific words. The second most popular expectation (of 33\% of respondents) is that a theory should support itself with a number of illustrative examples. In the third place the 1BA subjects mention the language and form in which a theory is presented - it should be straightforward, understandable, interesting, not too complex, not boring (referred to by $20 \%$ of respondents). The expectations of a more cognitive nature are rather infrequent; I have found three statements ( $10 \%$ of respondents) that may be recognized as related to a greater extent to cognition than to practice only. ${ }^{4}$

Even though the number of 2BA subjects that did not respond to Q4 in any way is greater than in the case of 1 BA group ( $26 \%$ vs $20 \%$ ), I perceive $2 \mathrm{BA}$ answers as slightly more cognition-oriented. The percentage of respondents aiming at deeper insight into the process of translation ${ }^{5}$ increases from $10 \%$ to $17 \%$. Nevertheless, practical dimensions remain the most important: $35 \%$ of respondents hope to learn about translation strategies and techniques; $622 \%$ of respondents expect a comprehensive theory to offer illustrative examples. The issue of the language and form is less important than for the $1 \mathrm{BA}$ group and is mentioned by $9 \%$ of $2 \mathrm{BA}$ respondents. What draws my attention is the fact that $13 \%$ of $2 \mathrm{BA}$ subjects expect exercises to put the theory into practice, which on the one hand indicates an incorrect understanding of Q4 (most probably the expectations about a theory were mistaken for expectations about a course in translation theory), but on the other hand may be interpreted as an unfulfilled need to see practical applications of translation theories.

The expectations of 3BA respondents seem to be expressed with more varied wording and thus at first glance they are more difficult to categorize. It should be underlined that every single subject provides an

4 (I expect a theory) to show different ways of translating the same text, so that is suits the target language / to explain why I should use these solutions / I want to compare the theory with different translations

5 Most often the respondents mentioned deeper understanding / help in understanding / being more conscious / being more aware.

6 Similarly to 1BA respondents, 2BA subjects do not use the metalanguage of translation studies too often - the most frequently used wording includes solutions to translation problems / manners / tricks / right ways / advice / dos and dont's. The word technique is used once only. 
answer to Q4, more often than in the case of 1BA and 2BA the answers are more elaborate, sometimes on the verge of being repetitive. The importance of practical instruction in available strategies and techniques ${ }^{7}$ is still central, even though the percentage of respondents that express this expectation is slightly lower than before (33\%). Again, as was the case with 1BA respondents, the expectation about the language of description is frequently mentioned: $29 \%$ of $3 \mathrm{BA}$ subjects hope for a simple / comprehensible / clear / not too complex form of a theory. The significance of examples has slightly diminished, although it is mentioned in the third place, by $19 \%$ of 3BA respondents. However, even though the frequency of references to translation strategies or examples seems a bit lower, I would argue that the expectations concerning applicability of a theory to translation practice are more general and recurrent (or even more desperate?) - as much as $48 \%$ of 3BA respondents raise the issue of practicality / usefulness / applicability. Such a high rate made me reanalyse the questionnaires of $1 \mathrm{BA}$ and $2 \mathrm{BA}$ in this respect. I discovered that the hopes for effective application of a theory to practice were already mentioned, although not in such a clear and straightforward way and wording. Having reread the answers closely I counted that in the case of $1 \mathrm{BA}$ the issue of practicability was mentioned by $23 \%$ of respondents. As far as the 2BA group is concerned, I decided to add to the initial $22 \%$ those respondents that referred to exercises (mentioned above), which raises the final percentage to $35 \%$.

In the 3BA answers the frequency of expectations that I perceive and categorize as cognition-oriented is much greater than in the case of 1BA and 2BA groups and amounts to $29 \%{ }^{8}$ Finally, $14 \%$ of subjects expressed a need to learn more about the history of translation as a field, which - again - may indicate a misinterpretation of Q4, but on the other hand may be a signal of broadening perspective and experience, as well as changing perception of translation, viewed no longer as just a craft.

7 There is an observable shift in the wording used while referring to translation procedures, in comparison with $1 \mathrm{BA}$ and $2 \mathrm{BA}$ groups. More than half of the 3BA respondents that mention this issue use the terms strategies, methods or techniques. Other lexical choices are: appropriate ways, problematic issues.

8 Apart from answers using expressions with understand / being aware, I have categorized as cognition-oriented phrases such as food for thought / inspiring questions / deep analysis / broadened perspective. 
As regards the expectations of $1 \mathrm{MA}$ respondents, the one concerning translation strategies and techniques ${ }^{9}$ is verbalized by $26 \%$ of subjects, the next $13 \%$ mention the need to learn about solutions to typical problems. Two other aspects, frequently brought up by BA-level respondents, i.e. the language / register in which a theory is presented, and examples to support the main tenets, are definitely less important to 1MA subjects: the hope for an interesting / simple / concrete form of delivery is expressed by $17 \%$, and the expectation to be provided with examples - by only $13 \%$. However, the expectation about general practicality and applicability of a theory, noticed as a new tendency in the case of the 3BA group, is this time even more conspicuous: it was articulated by $52 \%$ of $1 \mathrm{MA}$ subjects. The frequency of cognition-related expectations has slightly lowered, to the level of $26 \%$, but the answers that were categorized as such are more elaborate and varied ${ }^{10}$.

Some of the tendencies described above are also observable in the case of the 2MA group. The importance of specific instruction on detailed translation strategies and techniques ${ }^{11}$ is smaller: it was mentioned by $20 \%$ of subjects. However, the reference to general practicality and applicability is on the increase: as much as 55\% of $2 \mathrm{MA}$ respondents declare that this is one of their main expectations about a comprehensive translation theory. In comparison to the 1MA group, the significance of form and examples is greater for the 2MA group: the language of description that is clear / accessible / concise / easy to understand / easy to read and follow was important for $25 \%$ of $2 \mathrm{MA}$ respondents, whereas $30 \%$ of $2 \mathrm{MA}$ respondents state that an outline of a comprehensive translation theory should include illustrative examples. The fact that the percentage of cognition-related expectations is extremely low (5\%) is also worthy of mention.

9 In this group the use of metalanguage is predominant (strategies / techniques / methods / procedures).

10 In addition to already used phrases with understanding / explanation / conscious, 1MA respondents mention broadened horizons / enlightenment / better perception / different perspectives / self-development.

11 In comparison with 1MA group, the use of metalanguage in 2MA group is less consistent: along with the term technique the respondents frequently use the word solutions. 
The chart below is an attempt to collectively present the answers to $\mathrm{Q} 4$, in a way that would make it easy to observe the discrepancies between the choices of particular groups. The division into predominant types of expectations (strategies, form, examples, practicality, cognition) has been kept as in the verbal descriptions above. Additionally, the percentage of questionnaires with no answer to Q4 has been included.

Chart 13. The distribution of Q4 answers in particular groups of respondents

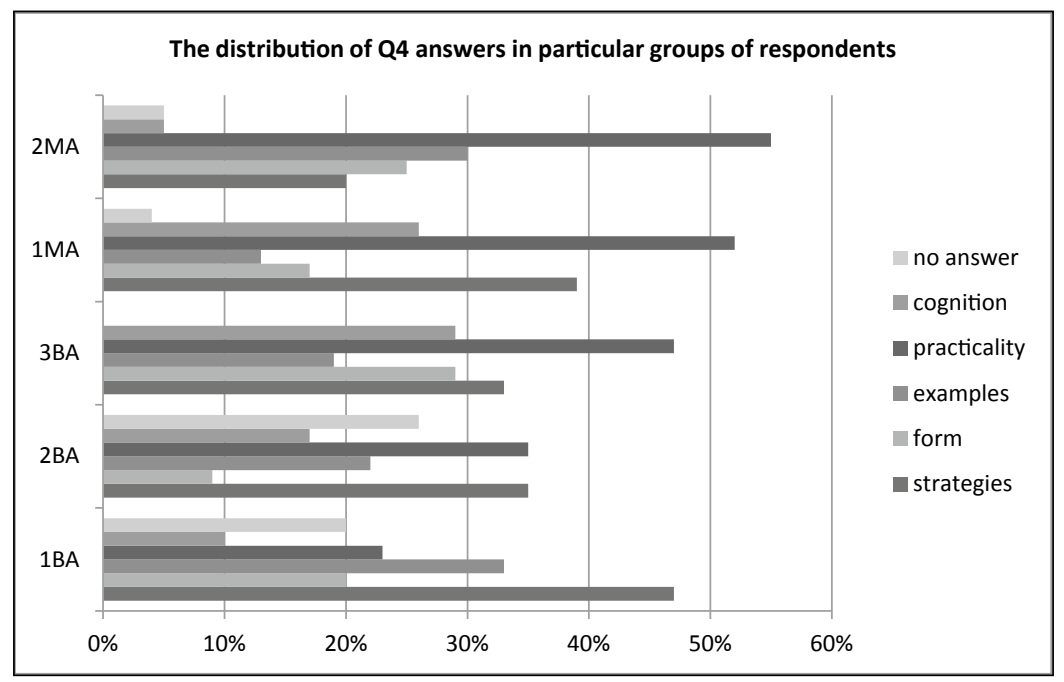

As has been already mentioned, the percentage of respondents omitting Q4 altogether decreases with growing experience ${ }^{12}$, which is not at all surprising: with time students become more self-aware and observant, sharpen their hierarchy of importance, and are more capable of using the metalanguage of translation.

12 Taking into account the outcomes of S2, it is assumed that in terms of experience MA-level respondents are in 50\% as unexperienced as 1BA respondents, and in $50 \%$ as experienced as $3 \mathrm{BA}$ respondents. It is further deduced that in the case of MA groups any departure from an outcome averaged in line with this half and half balance may be interpreted as related to growing experience of the respondents. 
The expectation that a comprehensive translation theory should provide its followers with an inventory of strategies decreases in popularity with growing experience, and is gradually replaced by a more general (and increasing) expectation about the practicality and usefulness of a translation theory.

The outcomes related to the importance of the language, register and form of a theory description are inconclusive within BA-level groups, although this expectation is increasingly frequent at MA-level.

The importance of examples accompanying theoretical statements in a theory description decreases among BA-level respondents, is lower than could have been expected in the case of 1MA group and rises for 2MA subjects.

The cognition-related dimension of a theory becomes increasingly important within the BA-level group, however, it is on the decrease in terms of popularity among MA-level respondents, which is further discussed in the Conclusions below.

\section{Conclusions}

According to the main assumption behind the study, the percentage of subjects convinced about the indispensability of translation theories should increase proportionally to their translation experience. However, the obtained results suggest that for some reason the opposite may be true.

Having considered the results of S2 and almost identical distribution of answers in each of the BA-level groups, it could have been expected that the Q1 answers of MA-level respondents would divide in a similar way. Contrary to this expectation, the choices of MA groups reveal that their attitude towards the usefulness of translation theories is much less enthusiastic. On the other hand, the answers to Q2 and Q3 give the impression that the respondents are not critical of the actual balance between practical and theoretical courses, as well as of the contents of translation theory courses offered in the programme. Combining these results with the answers to a more qualitative Q4, presented in detail above, I would dare to venture that the outcomes of the study lead us to the question of how?, not as much as what?. The decreasing conviction about translation theory indispensability and increasing need 
of visible practicality, supported with illustrative examples, may signal that the reason for students' incomplete satisfaction is possibly related to the manner of presenting particular theories, and not only to translation theories as such.

The answers to Q4 clearly demonstrate that gaining knowledge about possible translation solutions and behaviour in particular situations is one of the most frequently verbalized expectations of the subjects. It echoes the first of three current goals of translation theory as observed by Chesterman [2000: 48]: "(a) to describe what translators do, what strategies they use and what roles they play, under given linguistic and socio-cultural conditions." In my opinion this fact shows that translator trainees intuitively hold reasonable and realistic expectations for a comprehensive translation theory. What is more, the percentage of answers in the case of 1MA group ideally illustrates the heterogeneity of this group (please note the assumption from footnote 12): it reaches the level of $39 \%$, which is an average of $1 \mathrm{BA}$ and $3 \mathrm{BA}$ percentages ( $47 \%$ and $33 \%$ respectively). However, as has already been underlined, at both BA and MA levels this expectation gradually gives place to the one for usefulness and practicality. It may suggest that with time students become dissatisfied not as much with the answers they get as with the uncertainty of how to rely on them. This, along with the increasing need for illustrative examples declared by 2MA group, indicates that the popular method of translation theory teaching, still bearing strong traces of transmission [cf. e.g. Kiraly 2000: 22-23], does not produce satisfactory results. Even though it is commonly believed that the transmission model of education should be entirely a thing of the past [Pym, 2011: 475-489], it is not easy to make it happen, especially as regards translation theory teaching. The theory of translation is usually taught as a lecture, in the form of a separate course, not as a workshop integrated into a practical course. ${ }^{13}$

13 For the sake of the study I analysed the descriptions of translation programmes provided by almost 100 European and non-European tertiary education units that participated in the OPTIMALE project (2010-2013; www.translator-training. eu), made available on the OPTIMALE website (access: September 2013). It turned out that the majority of programmes (53\%) included at least one separate course in translation theory, delivered under different names. One third of the 
Obviously, as the study was conducted with the participation of subjects affiliated to the same university, its results should not be generalized. In order to obtain more conclusive data, it would be necessary to repeat the questionnaire with students in other translation programmes, or at least to repeat it after a few years, with new cohorts of students. Interestingly, the scope and outcomes of the study partly overlap with the research conducted by Wali [2015]. The author held a survey on selected aspects of teaching translation, analysed the answers of 19 trainers and 61 trainees affiliated to seven different post-graduate translation programmes in the UK, and compared them to the answers provided by 12 translation agencies. Three of the questions concerned translation theory teaching and application. The answers revealed significant discrepancies between the opinions of trainers and students (let alone the wide disparity between these and the standpoints of translation agencies). While the majority of teachers believe that after translation theory courses students normally understand theories and can apply them $(47.4 \%)$, the majority of students reveal that even though they understand theories, they cannot apply them (41\%), and the remaining $23 \%$ confess they do not understand theories and cannot apply them. This pessimistic view was not shared by a single teacher [Wali, 2015: 113]. As the author underlines, " $86.9 \%$ of students agree that they listen passively to the lecturer, and then they ask questions. This percentage of the students experienced the transmission approach [...]" [ibidem: 112]. Wali complements her quantitative data with a few direct quotations from the student surveys ${ }^{14}$, which echo some of the statements by $2 \mathrm{MA}$ subjects I found in my study: it seems to me that often theory is isolated from practice; theory of translation should not be taught separately.

As may be concluded, even though constructivism is not an easy option, taking into account the constraints on the functioning of contemporary universities, it seems optimal also for translation theory teaching.

programmes $(32 \%)$ did not offer a separate translation theory course, and the data provided by $15 \%$ of the participants was insufficient to categorize.

[The student] "«did not really make the connection between the various translation theories studied and the actual translation modules»; «There was a gap usually between practical classes and the lectures. They do not serve each other»" [Wali, 2015: 113-114]. 
The transmission model of theory teaching is still common, usually due to the disproportion between the amount of knowledge to be acquired and the amount of time available. Transmitting gives an illusion of obtaining ready-made answers to recurring queries in an efficient manner, but in fact - as the study shows - in the case of such an applied field as translation, its very nature may paradoxically cause resistance. What is more, encouraging and enabling students to learn from experience, creating situations in which they need to - in Pym's words - look at a view, generate and select, would most probably inspire them to not only learn tricks of the trade, but crave for a profound understanding of causes and effects. The rest of the already mentioned list of the goals translation theory is supposed to reach, presented by Chesterman [2000: 48], refers to increased awareness of all the mechanisms and factors behind the process of translation. The ability to explain, predict and evaluate is a great advantage that translation theory may offer. The surveyed students seemed to recognize this opportunity with their growing experience, and then to lose interest and become disillusioned. It is one of the most important tasks of translation theory teaching to maintain their curiosity and eagerness to not only know, but also understand.

\section{References}

Alves, F. (2003), "Triangulation in Process Oriented Research in Translation", in: Alves, F. (ed.), Triangulating Translation: Perspectives in Process Oriented Research, John Benjamins, Amsterdam-Philadelphia, pp. vii-X.

Antonini, R. (2011), "Natural Translator and Interpreter", in: Gambier, Y., Van Doorslaer, L. (eds.), Handbook of Translation Studies: Volume 2, John Benjamins, Amsterdam-Philadelphia, pp. 102-104.

Baer, B.J., Koby, G.S. (2003), "Introduction. Translation Pedagogy: the Other Theory", in: Baer, B.J., Koby, G.S. (eds.), Beyond the Ivory Tower. American Translators Association Scholarly Monograph Series, vol. XII, John Benjamins, Amsterdam-Philadelphia, pp. vii-xv.

Calzada Pérez, M. (2005), "Applying Translation Theory in Teaching", New Voices in Translation Studies, 1, pp. 1-11.

Chesterman, A. (1996), "Teaching Translation Theory: The Significance of Memes", in: Dollerup, C., Appel, V. (eds.), Teaching Translation and 
Interpreting 3. New Horizons. Papers from the Third Language International Conference, John Benjamins, Amsterdam-Philadelphia, pp. 63-71.

Chesterman, A. (2000), Memes of Translation. The spread of ideas in translation theory, John Benjamins, Amsterdam-Philadelphia.

Chesterman, A. (2007), "On the Idea of a Theory", Across Languages and Cultures, 8 (1), pp. 1-16.

Chesterman, A., Wagner, E. (2002), Can Theory Help Translators? A Dialogue Between the Ivory Tower and the Wordface, St. Jerome, Manchester-Kinderhook.

Gentile, A. (1996), “Translation Theory Teaching”, in: Dollerup, C., Appel, V. (eds.), Teaching Translation and Interpreting 3. New Horizons. Papers from the Third Language International Conference, John Benjamins, Amsterdam-Philadelphia, pp. 55-62.

Hansen, G. (2005), "Combination and Triangulation of Methods and Data", [on-line] http://www.est-translationstudies.org/resources/research_issues/ combination\%20and\%20triangulation.html - 21.03.2013.

Harris, B. (1976), “The Importance of Natural Translation”, Working Papers on Bilingualism, 12, pp. 96-114.

Kiraly, D. (2000), A Social Constructivist Approach to Translator Education. Empowerment from Theory to Practice, St. Jerome, Manchester-Northampton.

Lederer, M. (2007), "Can Theory Help Translator and Interpreter Trainers and Trainees?", The Interpreter and Translator Trainer, 1(1), 15-35.

Piotrowska, M. (2016), Proces decyzyjny tlumacza: zarys metodyki nauczania przektadu, C.H. Beck, Warszawa.

Pym, A. (2010), Exploring Translation Theories, Routledge, London.

Pym, A. (2011), “Training Translators”, in: Malmkjær, K., Windle, K. (eds.), The Oxford Handbook of Translation Studies, Oxford University Press, Oxford, 475-489.

Robinson, D. (1991), The Translator's Turn, John Hopkins University Press, Baltimore.

Shiyab, S. (1996), "The Importance of Teaching Translation Theory", Babel, 42(3), 166-173.

Wali, S. (2015), "A Comparative Study of Approaches Adopted in Translator Training Programmes in the UK”, in: Bączkowska, A. (ed.), Perspectives on Translation, Cambridge Scholars, Newcastle upon Tyne, 103-126. 
STRESZCZENIE

\section{Teoria przekładu z perspektywy studenta: niezbędna} czy niepotrzebna?

Artykuł przedstawia i analizuje wyniki badania ankietowego przeprowadzonego wśród studentów translatoryki na studiach licencjackich i magisterskich którego celem było poznanie opinii badanych adeptów na temat przydatności teorii przekładu. Zgodnie z początkowym założeniem świadomość znaczenia wiedzy teoretycznej wzrasta wraz z nabywanym doświadczeniem, jednak wyniki badania sugerują, że charakter tej korelacji jest bardziej złożony. Autorka podejmuje próbę określenia czynników, które mogą mieć wpływ na analizowany związek i wyrażane przez badanych poglądy.

Słowa kluczowe: teoria przekładu, nauczanie przekładu, adept przekła$\mathrm{du}$, transmisja wiedzy, konstruktywizm

\section{SUMMARY}

The paper presents and analyses the outcomes of a survey study conducted with the participation of BA and MA students in a translation programme, aimed at gaining insight into the students' views on translation theory usefulness. It was initially assumed that theory appreciation would develop along with growing translation experience, however, the nature of the predicted correlation appeared more complex. The author attempts to determine what factors may influence the observed interconnection and affect the subjects' opinions.

Key words: translation theory, translation teaching, novice translator, transmission, constructivism 